BMJ Open

Diabetes

Research

\& Care

\title{
Incidence of diabetes and prediabetes and predictors of glycemic change among South Asians in the USA: the MASALA study
}

\author{
Unjali P Gujral (D) , ${ }^{1}$ K M Venkat Narayan, ${ }^{2}$ Namratha R Kandula, ${ }^{3}$ Kiang Liu, ${ }^{4}$ \\ Alka M Kanaya ${ }^{5}$
}

\section{To cite: Gujral UP,}

Narayan KMV, Kandula NR, et al. Incidence of diabetes and prediabetes and predictors of glycemic change among South Asians in the USA: the MASALA study. BMJ Open Diab Res Care 2020;8:e001063. doi:10.1136/ bmjdrc-2019-001063

\section{- Additional material is} published online only. To view, please visit the journal online (http://dx.doi.org/10.1136/ bmjdrc-2019-001063).

Received 19 November 2019 Revised 26 March 2020 Accepted 6 June 2020
Check for updates

\section{(C) Author(s) (or their} employer(s)) 2020. Re-use permitted under CC BY-NC. No commercial re-use. See rights and permissions. Published by BMJ.

For numbered affiliations see end of article.

Correspondence to Dr Unjali P Gujral; ugujral@emory.edu

\section{ABSTRACT}

Introduction South Asians have a high prevalence of type 2 diabetes mellitus (T2DM). This may be associated with high rates of conversion through the natural history of disease. However, there is a paucity of data on prediabetes and T2DM incidence and related predictors in South Asians in the USA.

Research design and methods We estimated prediabetes and T2DM incidence after 5 years of follow-up in the Mediators of Atherosclerosis in South Asians Living in America study $(\mathrm{n}=481)$ and examined the associated correlates. We defined T2DM and prediabetes using the American Diabetes Association criteria. Prediabetes included isolated impaired fasting glucose (ilFG), isolated impaired glucose tolerance (iIGT) and combined IFG and IGT.

Results Overall, $152(32 \%, 95 \% \mathrm{Cl}: 27.6$ to 35.9$)$ individuals progressed either from normal glucose tolerance to prediabetes or T2DM, or from prediabetes to T2DM. In standardised logistic regression models controlling for age and sex, only hepatic fat attenuation (increased hepatic fat) (OR: 0.67 (95\% Cl: 0.55 to 0.87$)$ per SD, visceral fat area (OR: $1.36(95 \% \mathrm{Cl}: 1.06$ to 1.74$)$ per SD and hypertension (OR: 2.21 (95\% Cl: 1.44 to 3.40) were associated with any glycemic progression.

Conclusions South Asians in the USA have a high incidence of dysglycemia. Hepatic and visceral fat may be factors in glycemic progression, and prevention efforts should target ectopic fat reduction.

\section{INTRODUCTION}

Individuals of South Asian ancestry (from Bangladesh, Bhutan, India, Pakistan, Nepal and Sri Lanka) are a rapidly growing segment of the US population. Between the years 2000 and 2010, the South Asian population in he USA increased by $68 \%$ and currently totals nearly 5.4 million. ${ }^{1}$ Based on prevalence data, South Asians in the USA are a highrisk population for type 2 diabetes mellitus (T2DM), ${ }^{2-5}$ but remain under-represented in clinical research and prospective studies. ${ }^{6}$ It is unknown if South Asians experience a relatively rapid rate of transition through the

\section{Significance of this study}

What is already known about this subject?

- Based on prevalence data, South Asians in the USA are a high-risk population for type 2 diabetes mellitus.

What are the new findings?

- In this longitudinal study of immigrant South Asians in the USA, after a mean 5 years of follow-up, approximately one-third of participants had some form of glycemic conversion.

- After adjusting for age and sex, ectopic fat depots and hypertension were strongly associated with glycemic progression.

- After adjusting for relevant covariates, insulin secretion was associated with regression from prediabetes to normal glucose tolerance.

How might these results change the focus of research or clinical practice?

- Prevention efforts to reduce diabetes and prediabetes incidence in South Asian Americans should focus on efforts targeting ectopic fat reduction and improvements in beta-cell function and preservation through diet and physical activity interventions.

natural history of T2DM development, and if they have high rates of incident prediabetes and diabetes. A recent population-based study from urban South India assessed the incidence rates of diabetes and the rates of conversion through differing stages of dysglycemia over a 10 -year period. ${ }^{7}$ Results of this study noted a high incidence rate of prediabetes and T2DM in this population coupled with rapid conversion from normal glycemia to prediabetes and from prediabetes to T2DM. ${ }^{7}$ However, there is a lack of information on whether the incidence of prediabetes and T2DM, and the rates of conversion are similarly high in South Asians in the USA. If so, this would point to innate susceptibilities 
in South Asians for rapid hyperglycemic conversion above and beyond factors associated with the environment. We therefore assessed the incidence of various categories of dysglycemia including isolated impaired fasting glucose (iIFG), isolated impaired glucose tolerance (iIGT), combined impaired fasting glucose and impaired glucose tolerance (IFG+IGT) and T2DM as well as the correlates of glycemic progression in a cohort of 644 South Asian individuals in the USA who completed an oral glucose tolerance test at both baseline and follow-up.

\section{RESEARCH DESIGN AND METHODS}

The design, sampling strategy, recruitment, enrollment and examination components of the Mediators of Atherosclerosis in South Asians Living in America (MASALA) study have been previously described in detail. ${ }^{8}$ In brief, MASALA is a community-based prospective cohort of South Asian Americans recruited from the greater San Francisco and Chicago areas. The MASALA study was designed to be similar to the Multi-Ethnic Study of Atherosclerosis (MESA), ${ }^{9}$ therefore only individuals who were aged $40-84$ years and had no previously known history of cardiovascular disease were eligible. In addition, participants had to self-report South Asian ethnicity (defined as having three or more grandparents born in either India, Pakistan, Nepal Bangladesh or Sri Lanka) and be able to speak and read English, Hindi or Urdu. Baseline recruitment occurred between October 2010 and March 2013. All participants were screened by telephone and then invited to either the Northwestern University or the University of California, San Francisco field center for a baseline clinical examination. ${ }^{8}$

Baseline questionnaires were completed with the assistance of bilingual study staff. Diet was assessed using the Study of Health Assessment and Risk in Ethnic Groups food frequency questionnaire, which was developed for and validated in South Asians to account for the distinct dietary intake of this population. ${ }^{8}$ Mean caloric intake was calculated as the sum of the product of the frequency of consumption, nutrient composition and portion size of each item across all foods. ${ }^{10}$

Blood pressure was measured after a 5 min seated rest and was assessed with and automated blood pressure machine (V100 Vital Signs Monitor, GE Healthcare). Three measures of seated blood pressure were taken and the average of the last two readings were used to determine systolic and diastolic blood pressure. Participant height was measured using a stadiometer while weight was measured using a standing balance beam or digital scale. Body mass index (BMI) was calculated as weight in kilograms divided by height in square meters. Waist circumference was assessed using a flexible tape measure at the site of maximum circumference, halfway between the lower ribs and the anterior superior iliac spine. Waist circumference was measured twice and the average of the two measures was used in the analysis.
After a 12-hour overnight fast, a $75 \mathrm{~g}$ oral glucose tolerance test was administered to participants without previously diagnosed diabetes who were willing and able to participate in the glucose challenge. Blood samples were obtained from a peripheral vein just before glucose ingestion as well as $30 \mathrm{~min}$ and at $120 \mathrm{~min}$ postchallenge for plasma glucose measurements which were measured using the hexokinase method. Serum insulin was measured by the sandwich immunoassay method (Roche Elecsys 2010; Roche Diagnostics). Total cholesterol, highdensity lipoprotein cholesterol and triglyceride levels were analyzed using enzymatic methods. Low-density lipoprotein cholesterol concentrations were calculated. The Millipore Luminex adipokine panel A (EMD Millipore) was used to measure adiponectin and resistin. ${ }^{11}$

CT scans of the abdomen (Philips Medical Systems; Toshiba Medical Systems; Siemens Medical Solution) were used to assess abdominal visceral, subcutaneous and intermuscular fat area. Non-contrast cardiac CT images using a cardiac-gated CT scanner (Phillips 16D scanner or Toshiba MSD Aquillion 64 at the University of California San Francisco and Siemens Sensation Cardiac 64 at Northwestern University) to assess pericardial fat volume and hepatic fat attenuation. ${ }^{12}$ Specifically, intrahepatic fat was measured by quantifying radiographical hepatic fat attenuation (or density of tissue relative to surrounding tissues), with lower attenuation indicating more liver fat. ${ }^{12}$

After approximately 5 years, participants were invited back for a follow-up visit. Identical protocols for the physical examination, questionnaire and laboratory measures were conducted at baseline and follow-up, aside from 30 min glucose, which was only measured at baseline.

Glycemic status was defined according to American Diabetes Association criteria. ${ }^{13}$ Diabetes was defined as previous physician diagnosis, the use of glucose-lowering medications or fasting plasma glucose $\geq 7.0 \mathrm{mmol} / \mathrm{L}$ or a 2-hour postchallenge glucose $\geq 11.1 \mathrm{mmol} / \mathrm{L}$. Prediabetes was defined as fasting plasma glucose between 5.6 and $6.9 \mathrm{mmol} / \mathrm{L}$ and normal 2-hour postchallenge glucose (iIFG); or a 2-hour postchallenge glucose between 7.8 and $11.0 \mathrm{mmol} / \mathrm{L}$ with normal fasting plasma glucose (iIGT); or fasting plasma glucose between 5.6 and $6.9 \mathrm{mg} / \mathrm{dL}$ and 2-hour postchallenge glucose between 7.8 and $11.0 \mathrm{mmol} / \mathrm{L}$ (IFG+IGT). Normal glycemia was defined as fasting glucose $<5.6 \mathrm{mmol} / \mathrm{L}$ and 2-hour post challenge glucose $<7.8 \mathrm{mmol} / \mathrm{L}$.

$\beta$-Cell function was estimated by the oral disposition index $\left(\mathrm{DI}_{\mathrm{o}}\right)$ and was calculated as $\left(\Delta \mathrm{I}_{0-30} / \Delta \mathrm{G}_{0-30}\right) \times(1 /$ fasting insulin $)^{14}$ as well homeostasis model assessment (HOMA) of $\beta$-cell function was which was calculated as $\left(20 \times \mathrm{I}_{0}(\mu \mathrm{IU} / \mathrm{mL}) / \mathrm{G}_{0}(\mathrm{mmol} / \mathrm{L})-3.5\right) \cdot{ }^{15}$ Insulin sensitivity was estimated using the Matsuda insulin sensitivity index $\left(\right.$ ISI $\left._{\mathrm{M}}\right)$ calculated as $10000 / \sqrt{ }$ (fasting glucose $\times$ fasting insulin $) \times($ mean oral glucose tolerance test (OGTT) glucose concentration $\times$ mean OGTT insulin concentration). ${ }^{16}$ HOMA-insulin resistance (IR) was calculated as $\left(\mathrm{I}_{0}(\mu \mathrm{IU} / \mathrm{mL}) \times \mathrm{G}_{0}(\mathrm{mmol} / \mathrm{L}) / 22.5\right) .{ }^{15}$ 
A total of 906 participants were enrolled in the MASALA study at baseline, and 157 individuals did not return for the follow-up visit. Of the 749 individuals at visit 2 , we excluded 105 participants who did not complete an oral glucose tolerance test at either baseline or follow-up. We also excluded an additional 163 individuals with prevalent T2DM at baseline. We therefore analyzed the remaining 481 participants for incident glycemic conversion.

\section{STATISTICAL ANALYSIS}

Study participants were characterized by glycemic status at baseline and follow-up. Baseline characteristics were described as means, geometric means and percentages by glycemic conversion status. Differences in these characteristics across glycemic conversion were assessed using $\chi^{2}$ test or analysis of variance as appropriate.

Person-years were calculated as the sum of years each person at risk contributed to the study between baseline and follow-up. Incidence rates were calculated as the number of new cases divided by person-years at risk of each glycemic conversion.

Person-year estimates for the incidence of diabetes or prediabetes were calculated from the baseline examination until the first occurrence of event incidence or last examination. Incidence of diabetes or prediabetes with 95\% CIs were be calculated per 1000 person-years with the number of individuals who developed the event as the numerator and total person time as the denominator.
Multivariable adjusted longitudinal regression models were used to assess the associations between risk factors and progression to diabetes or prediabetes. All analyses were performed using SAS V.9.3 (SAS Institute, Cary, North Carolina, USA).

\section{RESULTS}

Overall, after a mean 5 years of follow-up, 152 individuals $(31.6 \%)$ had any glycemic progression, either from normal glucose tolerance (NGT) to prediabetes or diabetes, or from prediabetes to T2DM (table 1).

The incidence rate from NGT to any prediabetes was 86.1 (95\% CI: 71.0 to 103.4 ) per 1000 person-years. The incidence rate from NGT to iIFG, 43.4 (95\% CI: 33.0 to 56.1) per 1000 person-years, was higher than that to iIGT, 19.7 (95\% CI: 13.1 to 28.7) per 1000 person-years. Those with IIFG had a lower rate of conversion to T2DM, 18.5 (95\% CI: 8.1 to 36.7 ) than those with iIGT, 42.6 (95\% CI: 26.0 to 66.0$)$ or combined IFG+IGT, 63.5 (95\% CI: (35.3 to 105.9). The overall incidence rate to T2DM from either NGT or prediabetes was 18.9 (13.9 to 25.3) per 1000 person-years.

In examining rates of regression from prediabetes to NGT or from T2DM to prediabetes, we found an incidence rate of regression from prediabetes to NGT of 39.8 (95\% CI: 28.9 to 53.7) per 1000 person-years. The incidence rate of regression was higher from IGT to NGT (56.8 (95\% CI: 37.3 to 83.3$)$ ) per 1000 person-years

\begin{tabular}{|c|c|c|c|c|c|c|}
\hline $\begin{array}{l}\text { Glucose tolerance } \\
\text { status at baseline }\end{array}$ & $\mathbf{N}$ & $\begin{array}{l}\text { Person- } \\
\text { years }\end{array}$ & $\begin{array}{l}\text { Glucose tolerance status } \\
\text { at follow-up }\end{array}$ & $\begin{array}{l}\text { Number of } \\
\text { outcomes }\end{array}$ & $\begin{array}{l}\text { Rate per } 1000 \\
\text { person-years }\end{array}$ & $95 \% \mathrm{Cl}$ \\
\hline \multirow[t]{6}{*}{ NGT } & 268 & 1266 & ilGT & 25 & 19.7 & 13.1 to 28.7 \\
\hline & & 1266 & ilFG & 55 & 43.4 & 33.0 to 56.1 \\
\hline & & 1266 & IFG+IGT & 29 & 22.9 & 15.6 to 32.5 \\
\hline & & 1266 & Any prediabetes & 109 & 86.1 & 71.0 to 103.4 \\
\hline & & 1266 & T2DM & 6 & 4.7 & 1.9 to 9.9 \\
\hline & & 1266 & $\begin{array}{l}\text { Any glycemic progression (to } \\
\text { prediabetes or T2DM) }\end{array}$ & 115 & 90.8 & 75.3 to 108.6 \\
\hline \multirow[t]{2}{*}{ ilFG } & 81 & 377 & T2DM & 7 & 18.5 & 8.1 to 36.7 \\
\hline & & 377 & NGT & 10 & 26.5 & 13.4 to 47.2 \\
\hline \multirow[t]{2}{*}{ ilGT } & 89 & 423 & T2DM & 17 & 40.2 & 24.2 to 63.1 \\
\hline & & 423 & NGT & 24 & 56.8 & 37.3 to 83.3 \\
\hline \multirow[t]{2}{*}{ IFG+IGT } & 44 & 205 & T2DM & 13 & 63.5 & 35.3 to 105.9 \\
\hline & & 205 & NGT & 6 & 29.3 & 11.9 to 60.9 \\
\hline \multirow[t]{2}{*}{ Any prediabetes } & 244 & 1004 & T2DM & 37 & 36.8 & 26.3 to 50.2 \\
\hline & & 1004 & NGT & 40 & 39.8 & 28.9 to 53.7 \\
\hline NGT or any prediabetes & 482 & 2271 & T2DM & 43 & 18.9 & 13.9 to 25.3 \\
\hline NGT or any prediabetes & 482 & 2271 & Any glycemic progression & 152 & 66.9 & 56.9 to 78.2 \\
\hline \multirow[t]{2}{*}{ T2DM } & 163 & 779 & NGT & 1 & 1.3 & 0.1 to 6.3 \\
\hline & & 779 & Any prediabetes & 9 & 11.6 & 5.6 to 21.2 \\
\hline
\end{tabular}

ilFG, isolated impaired fasting glucose; ilGT, isolated impaired glucose tolerance; MASALA, Mediators of Atherosclerosis in South Asians Living in America; NGT, normal glucose tolerance; T2DM, type 2 diabetes mellitus. 
compared with IFG to NGT (26.5 (95\% CI: 13.4 to 47.2$)$ ) per 1000 person-years or IFG+IGT to NGT $(29.3$ (95\% CI: 11.9 to 60.9$)$ ) per 1000 person-years. Incidence rates of regression from T2DM to prediabetes or NGT were lower than those from prediabetes to NGT.

Among those with NGT at baseline, those who converted to prediabetes had a higher mean waist circumference, fasting glucose, fasting insulin, pericardial fat volume, HOMA-IR and lower ISI $_{M}$ compared with those who remained normal glycemia (online supplementary table 1). Mean DI was lowest in those who converted to iIGT or IFG+IGT. Subcutaneous fat area was higher in those who converted to iIGT, while visceral fat area was higher in those who converted to iIFG, IFG+IGT or T2DM. Hepatic fat attenuation was lowest (suggesting higher fat content in the liver) in those who converted to iIGT.

Among those with prediabetes at baseline, compared with those who regressed to NGT, visceral fat area, pericardial fat volume, triglycerides and the prevalence of hypertension were higher in all those who converted to T2DM. Those who converted to T2DM also had the highest mean levels of 2-hour postchallenge glucose, fasting insulin, HOMA-IR and a lower DI and ISI $_{M}$ then those who regressed to NGT. Hepatic fat attenuation was lower in those who converted to T2DM from iIGT or IFG+IGT but not in those who converted from iIFG compared with those who regressed to NGT.

Factors that were significantly different at $\mathrm{p} \leq 0.05$ between those who had a glycemic conversion and those who did not were included in multivariable logistic regression models. Backwards stepwise elimination was used to remove variables with a $p>0.05$ from the model to retain only the most relevant covariates along with age, sex and duration of follow-up (table 2).

\section{DISCUSSION}

In this longitudinal study of immigrant South Asians in the USA, after a mean 5 years of follow-up, approximately one-third of participants had some form of glycemic conversion, either from NGT to prediabetes or diabetes, or from prediabetes to overt T2DM. There was also a high incidence rate of regression, particularly from prediabetes to NGT. We found that after adjusting for age and sex, ectopic fat depots and hypertension were strongly associated with glycemic progression, with hepatic fat being more associated with progression from prediabetes to T2DM, and visceral fat area being more strongly associated with any progression from NGT. Furthermore, DI at baseline, which is a measure of insulin secretion was strongly associated with regression from prediabetes to NGT.

Our finding suggest that glycemic progression in South Asians is more rapid than that found in whites, but is similarly high to that found in other minority race/ ethnic populations. A study assessing the incidence rate of diabetes after 4.7 years of follow-up in MESA found an overall incidence rate of 16.8 per 1000 person-years among members from four different race/ethnic groups. ${ }^{17}$ When stratified by race/ethnicity, AfricanAmerican and Hispanics had similarly high incidence rates of T2DM (21.6 per 1000 person-years and 21.9 per 1000 person-years, respectively), while whites and Chinese Americans had lower incidence rates (11.1 per 1000 person-years and 16.2 per 1000 person-years, respectively) ${ }^{17}$ compared with 18.9 per 1000 personyears in our study of South Asians. These findings suggest a high incidence of diabetes in similarly aged race/ethnic minorities in the USA including South Asians. However, the MESA study did not include 2-hour glucose tolerance tests in its definition of diabetes, and therefore the results between the two studies may not be directly comparable. An additional study estimating the incidence of diabetes among specific subgroups of Asian Americans and Pacific Islanders in a multiethnic population in the USA with uniform access to healthcare also noted a higher incidence rate of T2DM in South Asians compared with several other race/ethnic groups. ${ }^{18}$ The incidence rate reported for South Asians was 17.16 per 1000 person-years, which is lower than in the current study, and may be attributed to the use of the 2-hour glucose tolerance test included in the MASALA study compared with use of fasting glucose, hemoglobin A1c or medical diagnoses in the healthcare records in the Kaiser study. While little is known about the prevalence of diabetes in various Asian subgroups in the USA, recent data suggest considerable variation, with East Asians having the lowest prevalence at $7.2 \%$, comparable to non-Hispanic whites, while South Asians and Southeast Asians have the highest prevalence of $15.4 \%$ and $14.1 \%$, respectively. ${ }^{19}$ The high incidence rate of T2DM in South Asians is particularly alarming given that the prevalence in this population is likely to continue to grow.

When comparing the findings of our study with that of a cohort of South Indians in Chennai, India, we noted that the T2DM incidence rate from prediabetes was lower in South Asians in the USA compared with native South Indians (36.8 compared with 64.8 per 1000 person-years), however the incidence rate of prediabetes is much higher (86.1 compared with 17.5 per 1000 person-years). ${ }^{20}$ These results mirror our previous findings of a lower T2DM prevalence in US-based South Asians but a lower prediabetes prevalence compared with those living in Chennai, India, ${ }^{21}$ thereby suggesting that while South Asians have a high diabetes risk both in India and the Diaspora, there may be a possible shift in the relationship between migration and diabetes risk. The relatively high educational attainment, socioeconomic status (SES) and healthcare access of South Asian immigrants in the USA and in the MASALA study cohort may be a factor in slowing the transition from prediabetes to diabetes in those in the USA compared with in South Asia. Additional studies that include South Asians with greater SES variation are needed to better identify the gene-environment and 
Table 2 Factors related to any incident glycemic progression (A), any progression from NGT (B) and progression from prediabetes to diabetes $(C)$ and any regression from predibetes to NGT (D) between baseline and follow-up, MASALA study

\begin{tabular}{ll}
\hline Full model & OR (95\% Cl) \\
\hline A. & $\begin{array}{l}\text { Any glycemic progression } \\
\text { Full model }\end{array}$ \\
\hline Age & $1.05(0.81$ to 1.35$)$ \\
Sex & $1.96(1.10$ to 3.50$)$ \\
\hline Follow-up time & $1.30(0.98$ to 1.71$)$ \\
\hline Hypertension & $2.18(1.34$ to 3.54$)$ \\
\hline Waist circumference & $1.34(0.85$ to 2.10$)$ \\
\hline BMI & $0.89(0.80$ to 0.99$)$ \\
\hline Visceral fat & $1.33(0.92$ to 1.92$)$ \\
\hline Hepatic fat & $0.69(0.52$ to 0.91$)$ \\
\hline Pericardial fat & $1.08(0.78$ to 1.50$)$ \\
HDL & $0.80(0.60$ to 1.07$)$ \\
\hline Triglycerides & $1.00(0.79$ to 1.26$)$ \\
\hline Disposition index & $0.94(0.75$ to 1.18$)$ \\
Insulin sensitivity index & $0.97(0.62$ to 1.51$)$ \\
\hline
\end{tabular}

B.

\begin{tabular}{ll}
\hline Age & $1.53(1.07$ to 2.18$)$ \\
\hline Fex & $1.44(0.61$ to 3.38$)$ \\
\hline Hypertension & $1.16(0.77$ to 1.75$)$ \\
\hline Waist circumference & $2.19(1.07$ to 4.48$)$ \\
\hline BMI & $1.69(0.88$ to 3.21$)$ \\
\hline Visceral fat & $0.87(0.74$ to 1.03$)$ \\
\hline Hepatic fat & $1.48(0.85$ to 2.60$)$ \\
\hline Pericardial fat & $0.84(0.55$ to 1.29$)$ \\
\hline HDL & $0.91(0.56$ to 1.48$)$ \\
\hline Triglycerides & $0.92(0.61$ to 1.39$)$ \\
\hline Disposition index & $1.20(0.77$ to 1.86$)$ \\
\hline Insulin sensitivity index & $0.70(0.44$ to 1.12$)$ \\
\hline
\end{tabular}

C.

Age

Sex

Follow-up time

Hypertension

Waist circumference

Visceral fat

Hepatic fat

Pericardial fat

HDL

Triglycerides

Disposition index

Insulin sensitivity index
Any progression from NGT Full model

1.53 (1.07 to 2.18 )

1.44 (0.61 to 3.38$)$

2.19 (1.07 to 4.48$)$

1.69 (0.88 to 3.21$)$

0.87 (0.74 to 1.03$)$

Any progression from prediabetes Full model

0.68 (0.40 to 1.17$)$

2.77 (0.92 to 8.32$)$

1.36 (0.79 to 2.35$)$

2.02 (0.81 to 4.99$)$

1.16 (0.49 to 2.75$)$

1.44 (0.72 to 2.87$)$

0.56 (0.35 to 0.92$)$

1.44 (0.78 to 2.64$)$

0.85 (0.47 to 1.55$)$

0.86 (0.53 to 1.40$)$

0.99 (0.58 to 1.70$)$

0.92 (0.31 to 2.72 )
OR $(95 \% \mathrm{Cl})$

Any glycemic progression

Reduced model

1.05 (0.85 to 1.30$)$

1.26 (0.82 to 1.94$)$

1.27 (0.99 to 1.64$)$

2.21 (1.44 to 3.40 )

$-$

-

1.36 (1.06 to 1.74$)$

0.67 (0.55 to 0.87 )

$-$

$-$

$-$

$-$

Any progression from NGT Reduced model

1.38 (1.03 to 1.84$)$

0.88 (0.49 to 1.58$)$

1.17 ( 0.82 to 1.67$)$

2.26 (1.22 to 4.19$)$

$-$

$1.71(1.21$ to 2.40$)$

$-$

$-$

$-$

$-$

$-$

$-$

Any progression from prediabetes

Reduced model

1.13 (0.77 to 1.63$)$

0.98 (0.45 to 2.16$)$

1.37 (0.87 to 2.14 )

$-$

$-$

$-$

0.57 (0.39 to 0.84$)$

$-$

$-$

-

-

- 
Table 2 Continued

\begin{tabular}{lll}
\hline D. & $\begin{array}{l}\text { Any regression from prediabetes } \\
\text { Full model }\end{array}$ & $\begin{array}{l}\text { Any regression from prediabetes } \\
\text { Reduced model }\end{array}$ \\
\hline Age & $0.96(0.60$ to 1.55$)$ & $0.87(0.59$ to 1.26$)$ \\
\hline Sex & $0.61(0.24$ to 1.55$)$ & $1.13(0.53$ to 2.43$)$ \\
\hline Follow-up time & $0.81(0.45$ to 1.43$)$ & $0.73(0.44$ to 1.22$)$ \\
\hline Hypertension & $0.35(0.12$ to 1.05$)$ & - \\
\hline Waist circumference & $1.06(0.57$ to 1.98$)$ & - \\
\hline Visceral fat & $0.61(0.29$ to 1.30$)$ & - \\
\hline Hepatic fat & $1.01(0.58$ to 1.74$)$ & - \\
\hline Pericardial fat & $0.76(0.37$ to 1.56$)$ & - \\
\hline HDL & $1.53(0.86$ to 2.72$)$ & - \\
\hline Triglycerides & $0.80(0.42$ to 1.53$)$ & - \\
Disposition index & $3.73(1.22$ to 11.40$)$ & $4.23(1.57$ to 11.40$)$ \\
Insulin sensitivity index & $1.39(0.52$ to 3.73$)$ & -
\end{tabular}

After adjusting for age, sex and duration of follow-up, hepatic fat attenuation (OR: 0.67 (95\% Cl: 0.55 to 0.87$)$ ), visceral fat area (OR: 1.36 (95\% Cl: 1.06 to 1.74$)$ ) and hypertension (OR: 2.21 (95\% Cl: 1.44 to 3.40$)$ ) were associated with any glycemic progression. Hepatic fat attenuation was associated with progression from prediabetes to T2DM, while visceral fat mass was associated with progression from NGT to prediabetes or T2DM. Disposition index was associated with regression from prediabetes to NGT (OR: 4.23 (95\% Cl: 1.57 to 11.40)). BMI, body mass index; HDL, high-density lipoprotein; MASALA, Mediators of Atherosclerosis in South Asians Living in America; NGT, normal glucose tolerance; T2DM, type 2 diabetes mellitus.

lifestyle exposures that underlie glycemic progression in this population.

The results of our study point to the association between ectopic fat and glycemic progression, particularly visceral and hepatic fat. However, there were no significant associations between central and overall obesity as measure by BMI and waist circumference with glycemic progression. While it is possible that correlations between overall and central obesity and ectopic fat dilute the association of BMI and waist circumference, we performed a sensitivity analysis and found only weak-to-moderate correlations between BMI and waist circumference and visceral fat mass, pericardial fat and hepatic fat attenuation. Therefore the associations between ectopic fat and glycemic progression are likely to be independent of overall and central obesity.

Similar results regarding the associations of ectopic fat with glycemic progression have been noted in other race/ethnic groups. A study assessing the predictors of incident diabetes in Japanese Americans found that intra-abdominal fat area was a significant predictor of diabetes incidence even after adjustment for BMI, total body fat area and subcutaneous fat area. ${ }^{22}$ A later study in Japanese Americans also noted that visceral adiposity increases the risk of IGT independent of IR and insulin secretion. ${ }^{23}$ Furthermore, a prospective study from Japan reported that hepatic fat was associated with incident IFG and T2DM in both men and women, and the impact of hepatic fat was stronger in those with a lower BMI. ${ }^{24}$ A study from Korea also noted that fatty liver increased the risk of incident T2DM after a period of 5 years, independently of IR. ${ }^{25}$ Several studies have reported increased levels of visceral and hepatic fat in
South Asians despite a relatively low BMI. ${ }^{12} 26-28$ Therefore, reducing ectopic fat, possibly through moderate weight loss, ${ }^{29}$ may be an important target in interventions aimed at reducing the incidence of diabetes and prediabetes, particularly in Asian populations. Our study also points to the association of higher insulin secretion and regression from prediabetes to NGT. Therefore, efforts aimed at improving and/or preserving insulin secretion are important considerations in terms of slowing or reversing disease progression in this population.

Our study has several strengths in that it is the first to longitudinally examine the incidence of prediabetes and T2DM in a cohort of South Asians in the USA using objective measures of glycemia as well as several radiographic measures of body composition for the assessment of ectopic fat. A limitation of the study is that MASALA study comprised an on average high-income, high-education, middle-to-older age group of South Asians from the greater San Francisco Bay and Chicago areas, and the results may not be generalisable to South Asians in other parts of the USA who are younger and/ or with lower SES. However, the high risk for diabetes in South Asians in the Diaspora has been well documented ${ }^{3-5}$ and our study points to a rapid rate of conversion through the natural history of diabetes in this group. An additional limitation is that study analyses were limited to those who completed an oral glucose tolerance test at both baseline and follow-up. In a sensitivity analysis, we found that at baseline, those who did not complete the follow-up visit had a significantly lower mean fasting glucose than those who did complete follow-up, however there were no significant 
differences in baseline 2-hour glucose between the groups. Therefore, it is possible that those who did not return for follow-up may have had differing rates of glycemic progression than those who did. Additional longitudinal studies of glycemic progression in this population are thus warranted.

In conclusion, the results of our study suggest a high incidence rate of glycemic progression in South Asian Americans. Ectopic fat is strongly associated with glycemic conversion, with hepatic fat being more strongly associated with progression from prediabetes to T2DM, and visceral fat mass being more strongly associated with any progression from NGT. Our results also indicate that insulin secretion is associated with regression from prediabetes to NGT. Therefore, prevention efforts to reduce diabetes and prediabetes incidence in South Asian Americans should focus on efforts targeting ectopic fat reduction and improving or preserving insulin secretion through diet and physical activity interventions and/or pharmaceutical interventions.

\section{Author affiliations}

${ }^{1}$ Rollins School of Public Health, Hubert Department of Global Health, Emory University, Atlanta, Georgia, USA

${ }^{2}$ Hubert Department of Global Health, Emory RSPH, Atlanta, Georgia, USA ${ }^{3}$ Division of General Internal Medicine, Northwestern University, Chicago, Illinois, USA

${ }^{4}$ Department of Community Health \& Preventive Medicine, Northwestern University Medical School, Chicago, Illinois, USA

${ }^{5}$ Epidemiology and Biostatistics-Diabetes Center, University of California San Francisco, San Francisco, California, USA

Contributors UPG analyzed all data and prepared and edited the manuscript. KMVN provided insight as to data analysis and interpretation and edited the manuscript, NRK assisted with data collection and maintenance as well as interpretation of the results and editing of the manuscript. KL assisted with interpretation of the results and edited the manuscript. AMK secured funding for the study assisted with data collection and maintenance as well as interpretation of the results and editing of the manuscript.

Funding The MASALA study was supported by the NIH grant no. 1R01 HL093009. Data collection at UCSF was also supported by NIH/NCRR UCSF-CTSI grant number UL1 RR024131. Both UPG and KMVN are supported by the National Institute of Diabetes and Digestive and Kidney Diseases of the National Institutes of Health under Award Number P30DK111024. KMVN was supported by the National Heart, Lung, and Blood Institute of the National Institutes of Health under Award Number R01HL125442.

Disclaimer The sponsors did not play a significant role in the analysis, interpretation and presentation of these results.

Competing interests None declared.

Patient consent for publication Not required.

Ethics approval The study was approved by the University of California, San Francisco Human Research Protection Program Institutional Review Board (IRB), IRB\#: 10-00353, as well as the Institutional Review Board of Northwestern University, IRB\# \# iSTU00019837.

Provenance and peer review Not commissioned; externally peer reviewed.

Data availability statement Data are available on reasonable request.

Open access This is an open access article distributed in accordance with the Creative Commons Attribution Non Commercial (CC BY-NC 4.0) license, which permits others to distribute, remix, adapt, build upon this work non-commercially, and license their derivative works on different terms, provided the original work is properly cited, appropriate credit is given, any changes made indicated, and the use is non-commercial. See: http://creativecommons.org/licenses/by-nc/4.0/.
ORCID iD

Unjali P Gujral http://orcid.org/0000-0002-0352-813X

\section{REFERENCES}

1 U.S. Department of Commerce Economics and Statistics Administration. The Asian population. 24, 2010.

2 Creatore MI, Moineddin R, Booth G, et al. Age- and sex-related prevalence of diabetes mellitus among immigrants to Ontario, Canada. CMAJ 2010;182:781-9.

3 Gupta LS, Wu CC, Young S, et al. Prevalence of diabetes in New York City, 2002-2008: comparing foreign-born South Asians and other Asians with U.S.-born whites, blacks, and Hispanics. Diabetes Care 2011;34:1791-3.

4 Oza-Frank R, Ali MK, Vaccarino V, et al. Asian Americans: diabetes prevalence across U.S. and world Health organization weight classifications. Diabetes Care 2009;32:1644-6.

5 Chiu M, Austin PC, Manuel DG, et al. Deriving ethnic-specific BMI cutoff points for assessing diabetes risk. Diabetes Care $2011 ; 34: 1741-8$

6 Đoàn LN, Takata Y, Sakuma K-LK, et al. Trends in clinical research including Asian American, native Hawaiian, and Pacific Islander participants funded by the US National Institutes of health, 1992 to 2018. JAMA Netw Open 2019;2:e197432.

7 Anjana RM, Shanthi Rani CS, Deepa M, et al. Incidence of diabetes and prediabetes and predictors of progression among Asian Indians: 10-year follow-up of the Chennai urban rural epidemiology study (cures). Diabetes Care 2015;38:1441-8

8 Kanaya AM, Kandula N, Herrington D, et al. Mediators of atherosclerosis in South Asians living in America (MASALA) study: objectives, methods, and cohort description. Clin Cardiol 2013;36:713-20.

9 Bild DE, Bluemke DA, Burke GL, et al. Multi-Ethnic study of atherosclerosis: objectives and design. Am J Epidemiol 2002;156:871-81.

10 Wang ET, de Koning L, Kanaya AM. Higher protein intake is associated with diabetes risk in South Asian Indians: the metabolic syndrome and atherosclerosis in South Asians living in America (MASALA) study. J Am Coll Nutr 2010;29:130-5.

11 Shah AD, Vittinghoff E, Kandula NR, et al. Correlates of prediabetes and type II diabetes in US South Asians: findings from the mediators of atherosclerosis in South Asians living in America (MASALA) study. Ann Epidemiol 2015;25:77-83.

12 Shah AD, Kandula NR, Lin F, et al. Less favorable body composition and adipokines in South Asians compared with other US ethnic groups: results from the MASALA and MESA studies. Int $J$ Obes 2016;40:639-45.

13 American Diabetes Association. 2. classification and diagnosis of diabetes. Diabetes Care 2016;39(Suppl 1):S13-22.

14 Utzschneider KM, Prigeon RL, Faulenbach MV, et al. Oral disposition index predicts the development of future diabetes above and beyond fasting and 2-h glucose levels. Diabetes Care 2009;32:335-41.

15 Matthews DR, Hosker JP, Rudenski AS, et al. Homeostasis model assessment: insulin resistance and beta-cell function from fasting plasma glucose and insulin concentrations in man. Diabetologia 1985;28:412-9.

16 Matsuda M, DeFronzo RA. Insulin sensitivity indices obtained from oral glucose tolerance testing: comparison with the euglycemic insulin clamp. Diabetes Care 1999;22:1462-70.

17 Bertoni AG, Burke GL, Owusu JA, et al. Inflammation and the incidence of type 2 diabetes: the multi-ethnic study of atherosclerosis (MESA). Diabetes Care 2010;33:804-10.

18 Karter AJ, Schillinger D, Adams AS, et al. Elevated rates of diabetes in Pacific Islanders and Asian subgroups: the diabetes study of northern California (DISTANCE). Diabetes Care 2013;36:574-9.

19 Cheng YJ, Kanaya AM, Saydah S, et al. Prevalence of diagnosed diabetes and total diabetes among Asian Americans, 2011-2014. Diabetes 2018;67:310-OR.

20 Mohan V, Deepa M, Anjana RM, et al. Incidence of diabetes and prediabetes in a selected urban South Indian population (CUPS-19). $J$ Assoc Physicians India 2008;56:152-7.

21 Gujral UP, Narayan KMV, Pradeepa RG, et al. Comparing type 2 diabetes, prediabetes, and their associated risk factors in Asian Indians in India and in the U.S.: the CARRS and MASALA studies. Diabetes Care 2015;38:1312-8.

22 Boyko EJ, Fujimoto WY, Leonetti DL, et al. Visceral adiposity and risk of type 2 diabetes: a prospective study among Japanese Americans. Diabetes Care 2000;23:465-71.

23 Hayashi T, Boyko EJ, Leonetti DL, et al. Visceral adiposity and the risk of impaired glucose tolerance: a prospective study among Japanese Americans. Diabetes Care 2003;26:650-5. 
24 Yamada T, Fukatsu M, Suzuki S, et al. Fatty liver predicts impaired fasting glucose and type 2 diabetes mellitus in Japanese undergoing a health checkup. J Gastroenterol Hepatol 2010;25:352-6.

25 Sung K-C, Kim SH. Interrelationship between fatty liver and insulin resistance in the development of type 2 diabetes. J Clin Endocrinol Metab 2011;96:1093-7.

26 Mohan V, Farooq S, Deepa M, et al. Prevalence of non-alcoholic fatty liver disease in urban South Indians in relation to different grades of glucose intolerance and metabolic syndrome. Diabetes Res Clin Pract 2009;84:84-91.
27 Raji A, Seely EW, Arky RA, et al. Body fat distribution and insulin resistance in healthy Asian Indians and Caucasians. J Clin Endocrinol Metab 2001;86:5366-71.

28 Banerji MA, Faridi N, Atluri R, et al. Body composition, visceral fat, leptin, and insulin resistance in Asian Indian men. J Clin Endocrinol Metab 1999;84:137-44.

29 Chooi YC, Ding C, Chan Z, et al. Moderate weight loss improves body composition and metabolic function in metabolically unhealthy lean subjects. Obesity 2018;26:1000-7. 